« Notes and Discussions »

\title{
EVIDENCE AGAINST A GRID-ONLY APPROACH TO STRESS ASSIGNMENT*
}

\author{
W AYNE P. LAWRENCE \\ University of Auckland
}

In recent years much attention has been paid to the roles played by grids and trees in metrical phonology. The original formulation of a metrical theory with these two devices provides for an arboreal constituent structure, and a stratified metrical grid "which can be thought of as a hierarchy of intersecting periodicities (rather than constituents)" (Liberman \& Prince (1977: 333)). More than one researcher has been left with the feeling that with this dual representation, a certain degree of redundancy is inherent, and there has been evidence adduced to support an approach which does without the grid (e.g., Tanaka 1985) on the one hand, and one which does away with trees by constructing the grid directly from the phonological string (e.g., Prince 1983; Selkirk 1984) on the other. The latter theory, that which has no trees, has been argued for particularly forcefully, and Selkirk 1984 is a book of over four hundred pages which is to a large extent devoted to making explicit such a tree-less theory.

There are arguments against tree-less phonology (e.g., Halle 1984; AlMozainy, Bley-Vroman \& McCarthy 1985), but these arguments are based on the existence of a phonological constituent (the foot) which bounds accent movement. Direction of accent movement can therefore be predicted from the direction of branching of feet in the arboreal structure, but, as noted above, the grid is said not to be made up of constituents, so a grid-only theory would require an ad hoc (language specific) stipulation to account for the direction of accent movement. This is a valid argument against grid-only theories only if the grid is not modified to

* This is an enlarged version of a paper written at the University of Tsukuba in 1986. I am indebted to Shosuke Haraguchi and anonymous reviewers for helpful comments on the earlier version. 
reflect constituent structure (a possibility noted by Liberman \& Prince (1977: 313)), and if the direction of accent movement cannot be shown to be related to any independently required parameters. In this paper, however, I shall adopt a different tact and shall show that, even ignoring the question of constituent structure, grid-only theories require much more language-particular detail than do 'mixed' theories in order to account for word accentuation.

One example of a grid-only theory in action is the following from Italian (Selkirk (1984:50-1)). The word generativa has two possible accentuations, gènerativa and generativa. The rules of basic beat alignment and main word stress give $1 .^{1}$

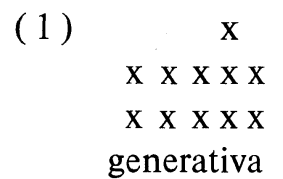

The Principle of Rhythmic Alternation (PRA) which defines an ideal where a strong beat is to be followed by a weak, and a weak may be preceded by at most one other weak, requires 1 to be adjusted to either 2 or 3 .

(2)

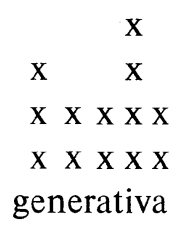

$$
\begin{array}{r}
\mathrm{X} \\
\mathrm{X} \times \\
\mathrm{X} \times \mathrm{x} \times \mathrm{x} \\
\mathrm{X} \times \mathrm{x} \times \mathrm{x} \\
\text { generativa }
\end{array}
$$

This adjustment is effected by Beat Addition (BA) 4, a Grid Euphony rule,
(4) a. left-dominant BA
b. right-dominant $\mathrm{BA}$

$$
\mathrm{x} x \Rightarrow \mathrm{x} x
$$

$x \Rightarrow x x$

the function of which is to bring the grid as close to the ideal as other rules and conditions permit. Optional application of BA would give 2 and 3 directly from 1, but if BA is considered to be obligatory (Selkirk (1984: 424-5) with discussion of this particular example), we derive 5 with

\footnotetext{
1 Syllable-timed languages have "only one basic beat rule, which specifies that every syllable will have a basic beat" (Selkirk (1984: 58)), and this is the second grid level in 1. The first metrical level is formed by the universal rule of Demibeat Alignment. Throughout this paper I shall, for consistency, assume that these two levels are present, but this is not crucial.
} 
two applications of BA, and Beat Deletion would apply to delete one of the adjacent added beats giving 2 and 3 . It is clear that left-dominant $\mathrm{BA}, 4 \mathrm{a}$, is being used here, and that it is being applied from left to right.

$$
\begin{gathered}
x \\
x \times \quad x \\
x \times \times x \times \\
x \times x \times x \\
\text { generativa }
\end{gathered}
$$

Spanish (examples and foot structure are from Harris 1983) appears to have a parallel phenomenon, ${ }^{2}$ the word generativo 'generative' being accented as gènerativo (colloquial) or genèrativo (rhetorical style) (Harris (1983: 86). Selkirk's grid-only approach would treat this word in the same fashion as the Italian example above. Using both tree structure and the grid, the two accentuations are derived from $6 .^{3}$

$$
\begin{array}{rr}
\text { word: } & \text { x } \\
\text { foot: } & \text { x x X } \\
\text { syllable: } & \text { x x x x x } \\
& \text { x x x x x } \\
& \text { generativo }
\end{array}
$$

There is a clash at the foot level which can be resolved by deleting either of the first two beats on that level, giving the attested forms. A longer word with two patterns of accentuation is gramaticalidad 'grammaticality', with gràmaticàlidád (colloquial) and gramàticàlidád (rhetorical style). Using foot structure and the grid, the basic structure is as in 7 , (7)

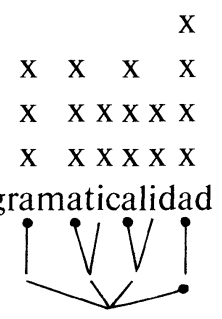

2 I have no data from Italian, so I use Spanish which I assume to be similar in the relevant respects. Even if they are not similar, the problem of how to account for Spanish stress patterns remains.

${ }^{3}$ For an outline of the tree and grid format used here, see Halle and Clements (1983: 15-25). 
and resolution of the clash at the foot level of the grid gives all and only the attested forms. On the other hand, using Selkirk's grid-only approach, in addition to the two correct forms, the unattested forms 9a and $9 \mathrm{~b}$ would also be generated, straightforwardly by optional application of BA, or by application of Beat Deletion on 8 , the structure formed by obligatory application of BA.

(8)

\begin{tabular}{|c|c|}
\hline & 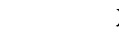 \\
\hline $\mathrm{X}$ & X X X \\
\hline $\mathrm{X}$ & X X X X \\
\hline $\mathrm{X}$ & X X X X \\
\hline
\end{tabular}

a.

$\begin{array}{ccr} & \\ X & \text { X } & \text { X } \\ \text { X } & \text { X X X X X X } \\ \text { X } & \text { X X X X X X }\end{array}$

*gramaticalidad b.

$$
\begin{array}{rr} 
& \text { X } \\
& \text { X X } \\
\text { X } & \text { X X X X X } \\
\text { X } & \text { X X X X X }
\end{array}
$$

*gramaticalidad

Let us consider how a grid-only theory of stress assignment could generate the attested forms without $9 \mathrm{a}$ and $9 \mathrm{~b}$. One possibility would be to make use of a domain-end prominence rule, the End Rule of Prince 1983 (Selkirk $(1984: 54,65)$ ), to enhance a beat onto the first syllable, and to use obligatory left-dominant BA from right-to-left. In Prince's framework, a "no-clash clause" prevents BA (Prince's Perfect Grid Construction) from "erecting a stress next to the initial stress" (Prince (1983: 49)), so the difference between the colloquial and rhetorical pronunciations would stem from optional (style conditioned) application of the End Rule. In Selkirk's model, BA may produce a clash, but the Textual Prominence Preservation Condition (Selkirk (1984: 56)) guarantees that only the grid position introduced by BA can be deleted, so application of the End Rule is style-regulated in the same way as it would be in Prince's framework. However, having optional application of the End Rule would allow languages with the alternation 10, where we have optional application of the End Rule on the right end of the word, right-to-left application of left-dominant BA, and main stress is determined by another application of the End Rule. I suspect that such languages do not exist, and I leave it to the interested reader to try to construct an arboreal structure (without extrametricality) ${ }^{4}$ which would give such an

${ }^{4}$ Extrametricality is excluded from consideration here as it can be used to produce the alternation in 10 in a grid-only theory just as easily as in a tree-only or mixed theory. This possibility should be excluded if 10 is not, as suspected, attested in natural language, and this can be done if it is assumed that extrametricality cannot be optional or cannot be affected by stylistic considerations. Either way, how extrametricality is constrained is a matter entirely divorced from the grid and arboreal structure. 
EVIDENCE AGAINST A GRID-ONLY APPROACH TO STRESS ASSIGNMENT 329

alternation.

(10)

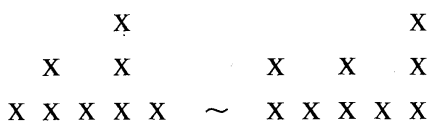

Application of the Spanish main word stress rule and left-dominant BA from right to left gives 11 .

$$
\begin{aligned}
& \mathrm{X} \\
& \begin{array}{lll}
X & X & X
\end{array} \\
& \mathrm{X} \text { X XXXX } \\
& \mathrm{X} \text { X X X X X }
\end{aligned}
$$

We would like to move the left-most third-level beat onto the first syllable, but the function of the rule Move $x$ (Beat Movement) is, by definition, to resolve clashes (Selkirk (1984: 55, 187); Prince (1983: 97)), and as there is no clash to be resolved, no $x$ should be moved (Selkirk (1984: 189)). However, if we broaden the scope of Move $x$ to allow it to apply even when there is no clash (but still with the condition that it not create a clash), ${ }^{5}$ we can generate the attested forms with optional application of Move $x$ as in 12 ,

$$
\begin{aligned}
& \begin{array}{llllllllllll} 
& & \mathrm{X} & & & \mathrm{X} & & & & \\
\mathrm{x} & \mathrm{x} & \mathrm{x} & \mathrm{x} & \mathrm{x} & \mathrm{x} & & \mathrm{x} & \mathrm{x} & \mathrm{x}
\end{array}
\end{aligned}
$$

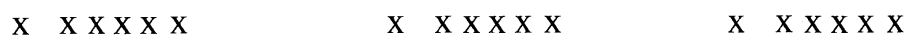

$$
\begin{aligned}
& \mathrm{x} \quad \mathrm{x} \times \mathrm{x} \times \mathrm{X} \text { Move } x \quad \mathrm{x} \quad \mathrm{x} \times \mathrm{x} \times \mathrm{x} \text { Move } x \quad \mathrm{x} \quad \mathrm{x} \times \mathrm{x} \mathrm{X} \mathrm{x}
\end{aligned}
$$

but in order to prevent generation of $9 \mathrm{a}$ as in 12 , it is necessary to restrict Move $x$ to applying once. This is not a universal constraint as Move $x$ is often permitted to "apply repeatedly to a structure, sometimes feeding itself" (Prince (1983:34)), so it would seem that we are now having to introduce much language particular detail (scope of Move $x$, restriction on repeated application) in order to take care of what, in a model where both arboreal structure and the grid play a role, is simply the resolution of a clash, nothing more, nothing less.

5 This possibility is suggested by Prince (1983: 51 footnote) for a hypothetical stress system based on that of Hawaiian. 


\section{REFERENCES}

Al-Mozainy, Hamza Qublan, Robert Bley-Vroman, and John J. McCarthy. 1985. Stress shift and metrical structure. LI 16.135-44.

Halle, Morris. 1984. Grids and trees in metrical phonology. ms., MIT. and G. N. Clements. 1983. Problem book in phonology. Cambridge, MA: MIT Press.

Harris, James W. 1983. Syllable structure and stress in Spanish: A nonlinear analysis. Cambridge, MA: MIT Press.

Liberman, Mark, and Alan Prince. 1977. On stress and linguistic rhythm. LI 8.249-336.

Prince, Allan S. 1983. Relating to the grid. LI 14.19-100.

Selkirk, Elisabeth O. 1984. Phonology and syntax: The relation between sound and structure. Cambridge, MA: MIT Press.

TANAKA, Shoichi. 1985. On the phrasal eurhythmicity in English. Tsukuba English Studies 4.47-61. 